\title{
Advances in ice radar studies of a temperate alpine glacier, South Cascade Glacier, Washington, U.S.A.
}

\author{
Andrew G. Fountain, ${ }^{1}$ Robert W. Jacobel ${ }^{2}$ \\ ${ }^{1}$ U.S. Geological Survey, P.O. Box 25046, MS-412, Denver, CO 80225, U.S.A. \\ ${ }^{2}$ Department of Physics, St Olaf College, Northfield, MN 55057, U.S.A.
}

\begin{abstract}
South Cascade Glacier, Washington, U.S.A., is one of the most extensively studied glaciers in the Western Hemisphere. In addition to mass-balance measurements, which date to 1958, numerous hydrological investigations have been carried out during the last three decades, and repeated ice-thickness determinations have been made using a variety of techniques. In the late 1960 s, the basal topography was initially determined by gravitimetric methods. In the mid-1970s some of the first depth measurements using radar on temperate ice were made. The basal topography was remapped soon after from a series of point radar measurements and boreholes drilled to the glacier bottom. During the 1990s, the ice thickness was remapped using digital recording of continuous profiles that obtained over 5000 ice-thickness measurements. Profiles have been corrected for the finite beamwidth of the antenna radiation pattern and reflections in steep terrain, resulting in a significantly improved depiction of the basal surface and internal structures. The map based on our recent radar profiles confirms the large-scale features of the basal topography previously depicted and reveals more structural detail. A bright reflector was detected at the base of the glacier and could be traced in adjacent profiles. Comparison with results from water-level measurements in boreholes drilled to the bed indicates that the reflector is a subglacial conduit.
\end{abstract}

\section{INTRODUGTION}

Ice radar is an increasingly valuable tool in the investigation of the geometry and internal structure of ice bodies. Since its initial application in Antarctica to determine the depth of ice (Evans, 1963), improvements in antenna design, microelectronics, and digital data acquisition and processing have increased the utility of ice radar and its application to all forms of ice including river and lake ice, as well as alpine glaciers (Bogorodsky and others, 1985). The practical application of ice radar to temperate alpine glaciers dates to experiments by Watts and England (1976) that showed a radar frequency of less than $10 \mathrm{MHz}$ was required to avoid the scattering caused by englacial voids. Since that time, small, portable and relatively inexpensive low-frequency ice radars have been developed, making depth soundings an integral part of most glacier studies. Increasing sophistication of digital electronic technology has significantly improved data-gathering rates, and post-processing techniques for digitally recorded profiles have markedly improved the quality of interpolated bed maps.

Many of these advances are illustrated by our recent studies on South Cascade Glacier which have been motivated by two goals. First, we wanted to re-map the basal topography of this glacier to determine whether advances in digital data-acquisition capabilities and post-processing significantly altered or improved previous depictions. Secondly, in coordination with a study of englacial and subglacial hydraulics, we hoped to interpret some of the radar signals in terms of hydrologic features and thus provide a means for calibrating the radar response to englacial and subglacial water.

\section{STUDY SITE}

South Cascade Glacier is a small valley glacier in the North Cascade Mountains of Washington, U.S.A. $\left(48^{\circ} 22^{\prime} \mathrm{N}\right.$, $\left.121^{\circ} 03^{\prime} \mathrm{W}\right)$. The glacier is $2.1 \mathrm{~km}^{2}$ in area with an elevation range from 1639 to $2126 \mathrm{~m}$ (Krimmel, 1995) and a maximum thickness of about $200 \mathrm{~m}$. This site was chosen for its relatively easy access and wealth of previous studies, which date from 1958. Previous maps of the basal topography were made from gravimetric measurements (Krimmel, 1970) and later by point radar-sounding measurements together with depths determined from boreholes drilled to the bed (Hodge, 1979). To help interpret the radar echoes in terms of hydrologic features in the ice, we rely on a number of previous hydrological studies of South Cascade Glacier, the most pertinent being that of Fountain (1994), which examined the subglacial hydraulic features.

\section{ICE RADAR AND FIELD METHODS}

The ice radar system developed at St Olaf College is based on the impulse transmitter design of Watts and England (1976), with the most recent version using a commercial pulser of similar design (Narod and Clarke, 1994). The recording system utilizes a generator-powered, $100 \mathrm{MHz}$ digital oscilloscope with the capability to rapidly stack (average) a large number of waveforms to improve the ratio of signal to noise. 
The number of waveforms stacked depends on the desired time/distance interval between depth sounding and the speed of travel over the surface. For most of our work on South Cascade Glacier, this was typically 256 waveforms stacked for every $2 \mathrm{~m}$ of surface travel. Each resulting stacked waveform was transferred from the oscilloscope via a general-purpose interface bus to random access memory storage in a portable computer. The waveforms were subsequently written to floppy disks at the end of each profile.

The frequencies of the radar are determined by the available dipole antenna lengths. In field applications on relatively thin glaciers like South Cascade we typically used $5 \mathrm{MHz}$ as the best compromise between spatial resolution and signal return strength. To facilitate moving the radar over the glacier's surface, the antennas are towed in an end-to-end configuration with the free-running transmitter pulled $50 \mathrm{~m}$ behind the larger receiver sled. The dipole radiation pattern for antennas lying at the ice/air interface is not uniform, nor (unfortunately) is it focused solely in the nadir (vertically downward) direction. Instead it also has strong lobes in the vertical plane containing the antennas both forward and aft of the transmitter/receiver, and to either side of this plane as well (Engheta and others, 1982). This increases the reception of energy returned from offnadir locations, and necessitates geometrical corrections to the profile data as discussed below.

The surface position of the ice radar was determined by standard optical surveying techniques. Recently, we have upgraded the system to utilize global positioning system (GPS) way points along the profiles, and a sensitive barometer to continuously record small changes in vertical position. Typically, at the end of each profile the data were displayed on the computer screen to check for any obvious problems. At the end of each day, adjacent radar profiles were compared to insure a continuity of change in basal topography. If errors were detected, such as loss of recording or mistakes in the surveying, or if the results did not seem reasonable, the profile was rerun the next day. Otherwise, the data were archived and new profiles were run the next day.

\section{DATA ACQUISITION AND PROCESSING}

Profile data were acquired primarily during four summer field seasons from 1990 to 1994 as one component of a larger project which included hydrologic studies, equipment development and various experiments with the radar. Figure 1 depicts the location of the radar profiles which include over 5000 ice-thickness measurements. Profile paths traversed the width of the glacier because profiles running the length of the glacier yielded multiple bed echoes as might be expected from a U-shaped valley where off-nadir echoes (in this case from either side) are more likely.

Figure $2 \mathrm{a}$ is a typical profile which shows multiple englacial echoes and a clear return from the bed. Returns at times greater than the bed echo are not sub-basal structure but are instead energy scattered or reflected from off-nadir targets within the ice at distances greater than to the bed. The clutter of englacial echoes is not random, and profiles repeated over the same path exhibit identical returns, indicating that we are detecting reflectors within the ice. Unlike the situation in polar ice where the substrate provides the largest amplitude echoes (Jacobel and others, 1993), here

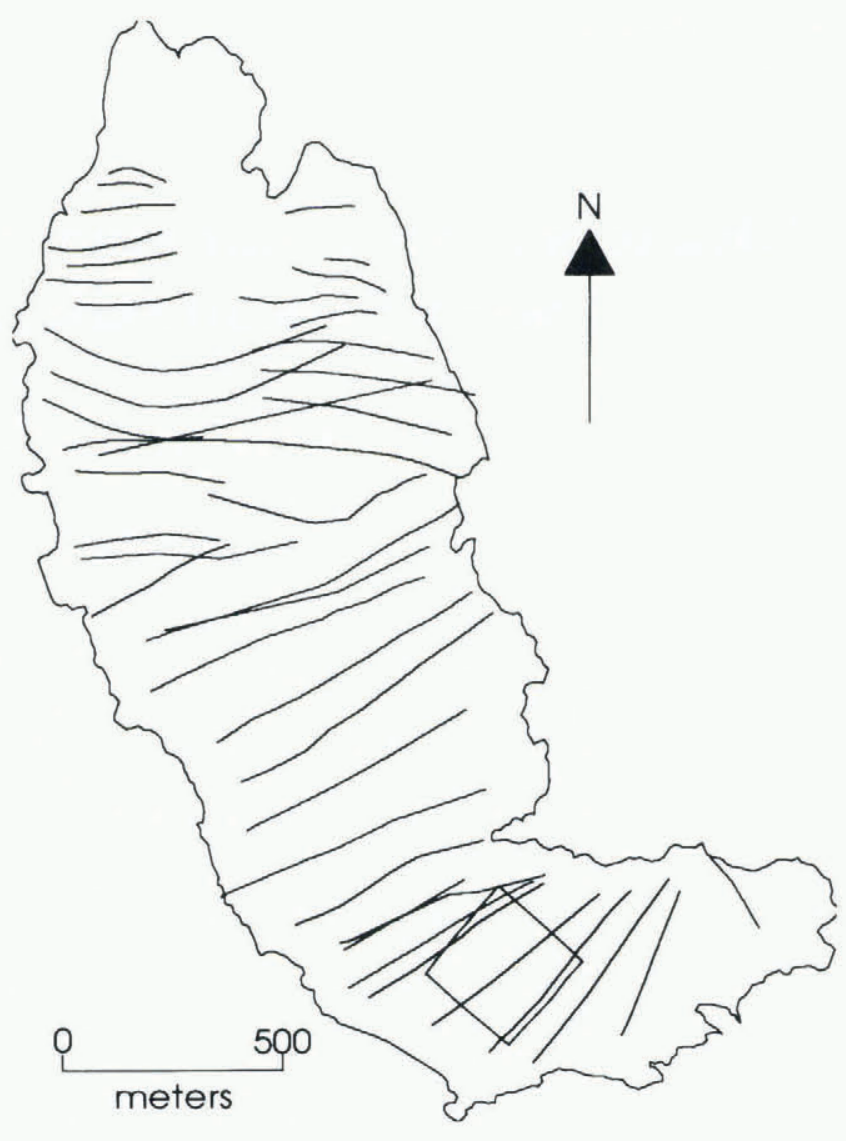

Fig. 1. The path of radar profiles superimposed on an outline of South Cascade Glacier as it was in 1985 (Krimmel, 1989). The square box outlines a grid region with closely spaced profiles (not shown). Areas of the glacier with no profiles are highly crevassed regions where the profiling radar could not be deployed.

the englacial-scattering targets return most of the energy, and the bed is distinguishable primarily because the weaker bed returns form a continuous line. This explains why some individual point radar measurements may not be reliable for picking a bedrock depth.

Before the profiles are measured to calculate ice depth, the data are first corrected for the finite beam pattern of the radar to properly locate the echo in a cartesian frame of reference. The raw profiles plot echoes in terms of twoway travel time in a radial direction from the radar. Although the echo location is constrained to the half-space beneath the radar, its precise direction within the half-space is unknown. It depends on the geometry of the scattering object or reflecting surface, and the echo strength also depends on the antenna radiation pattern as previously described.

The process of correcting echo location is called migration, and various methods to accomplish this have been worked out by seismologists who face a similar problem (Yilmaz, 1987). In the case of radar waves in ice, the medium itself (apart from water bodies) is largely homogeneous, and a single wave speed may be used, greatly simplifying the migration problem. In this circumstance the most efficient migration technique utilizes a two-dimensional fast Fourier transform to solve the problem in the frequency-wave-number domain (Yilmaz, 1987). In this method, energy from all possible off-nadir returns in the vertical plane containing the antennas is summed (migrated) to its corresponding nadir 


\section{Unmigrated}
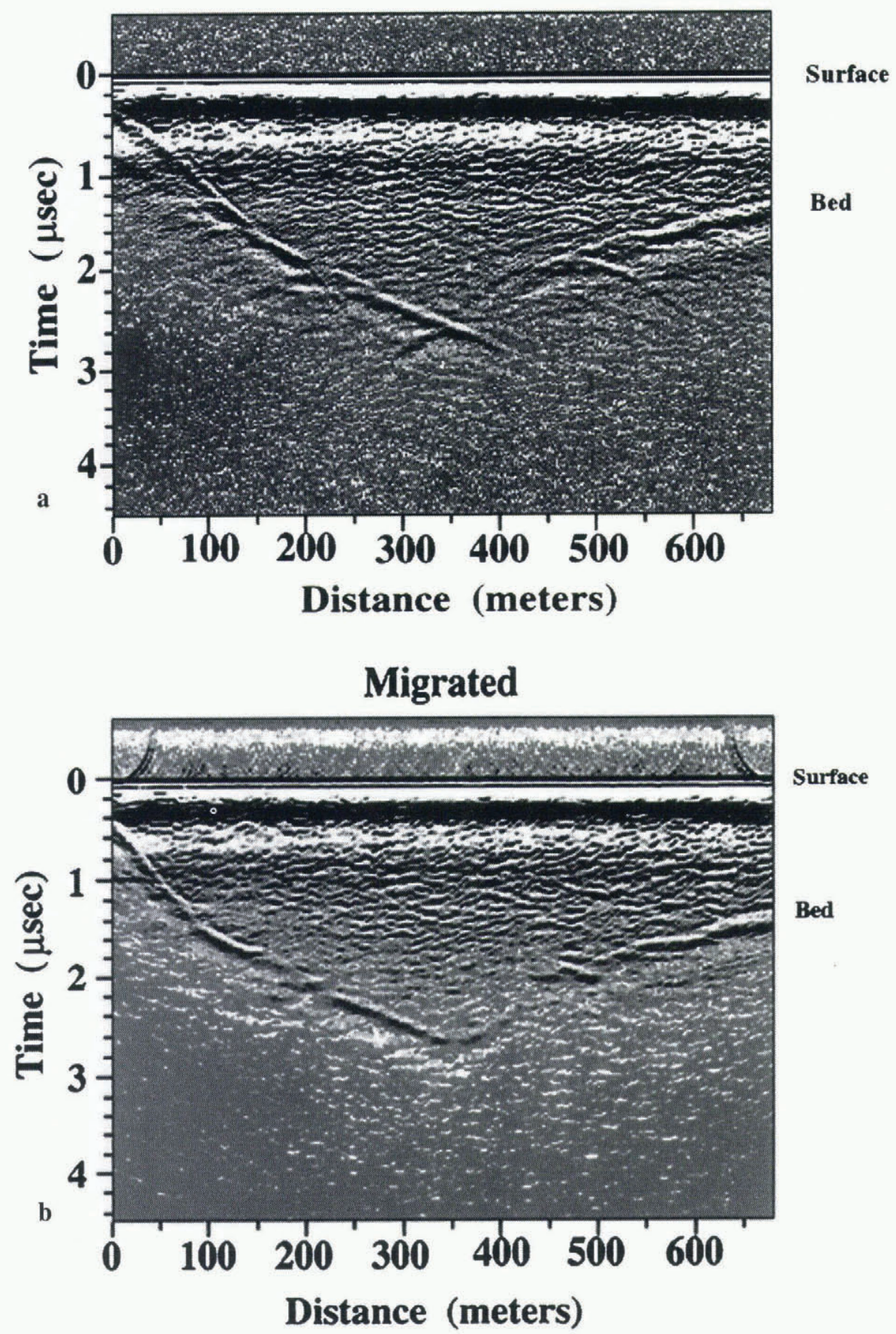

Fig. 2. (a) Typical example of a raw radar profile showing echoes from the bed and internal scattering sources. (b) Same profile after migration.

position. That is, energy returned from the same physical point in space which arrives at different times due to changes in the position of the transmitter/receiver pair is summed to a single point corresponding to an echo at the nadir location. The results are then transformed back into the space-time dimension and plotted.

Figure $2 \mathrm{~b}$ shows the results of migrating the profile in Figure 2a. Compared to the unmigrated profile, the slopes in basal topography are somewhat flattened, as echoes from the sides of the glacier are correctly interpreted. The accuracy of the glacier thickness is on the order of $1 \mathrm{~m}$, based on a comparison with several boreholes drilled to the glacier bottom in the enclosed basin. Less obvious in the profiles is the apparent change in echo strength from parts of the bottom of the glacier. Raw radar profiles exhibit artificially bright echoes from peaks in the subglacial terrain and weaker echoes from valleys, both of which are corrected by migration. Thus, migration is important for interpreting wave returns from valley glaciers where there are steep-sided slopes and substantial variations in subglacial topography.

The two-dimensional migration algorithm assumes that all the echoes arise from within the vertically oriented plane containing the antennas. Although echoes do occasionally arise from reflectors on either side, returns from those geometries are generally scattered or reflected away from the radar. The exception is echoes arising from a steep slope off to one side which strikes parallel to the direction of travel. Diffractors such as sharp bedrock topography to either side of the travel direction can similarly cause bright returns which are not from within the assumed plane. These echoes 


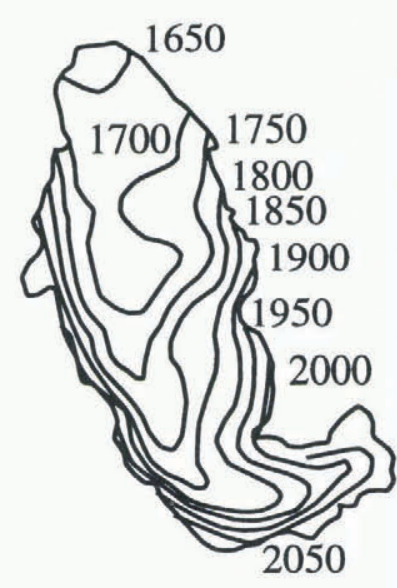

a

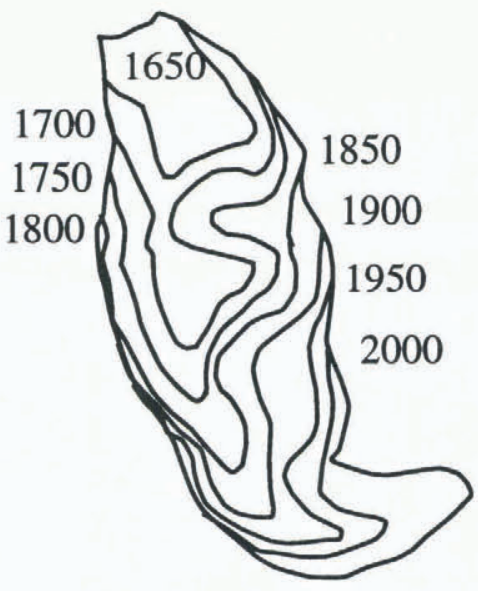

b

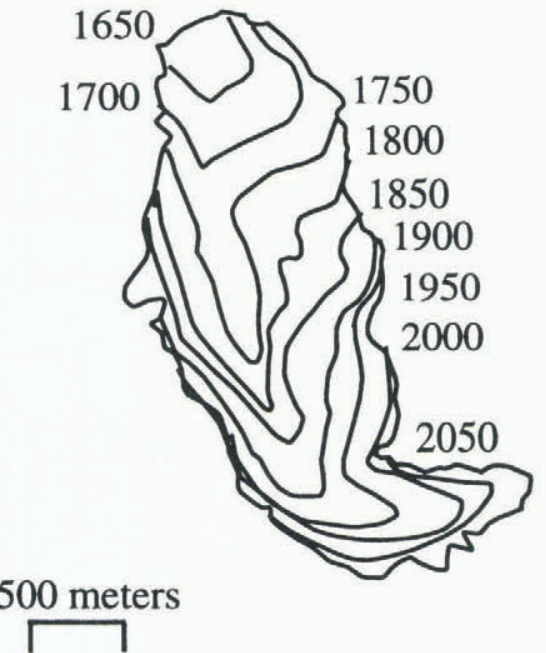

C

\begin{abstract}
Fig. 3. Elevation of the basal topography at South Cascade Glacier, in meters above mean sea level, for different mappings. (a) Basal topography based on radar profiling 1990-94 (this study). (b) Basal topography based on drilling and point radar soundings made in 1975 (Hodge, 1979). (c) Basal topography based on gravimetric measurements made in 1968 (Krimmel, 1970). The differences in glacier outline are due to glacier thinning. The contours for maps $(b)$ and $(c)$ were interpolated from the originals to provide $50 \mathrm{~m}$ interval.
\end{abstract}

are not correctly handled by the two-dimensional migration algorithm and give non-physical results which can occasionally cause difficulties in the bed interpretation. For this reason we typically run profiles perpendicular to the direction of greatest suspected bed slopes. In the upper part of the glacier where the valley axis makes a fairly sharp turn, profiles were run in perpendicular directions (indicated by the square in Figure 1) to unambiguously determine bedrock structure.

\section{RESULTS}

\section{Subglacial topography}

A map of the resulting basal topography is presented in Figure 3a. This map is based on the radar ice-thickness profiles shown in Figure 1 and surveyed surface elevations including the perimeter of the glacier. To produce the contour map, ice-thickness measurements were made from picks of the bed echo times using a computer algorithm constrained to search for maxima within a time window. This process seems to provide the optimal combination of consistency and human interpretation of bed echoes. The data were then interpolated onto an $x-y$ grid of points using a commercial software package. Results show a typical U-shaped valley with one prominent enclosed basin, within the $1700 \mathrm{~m}$ contour. The minimum elevation within the enclosed basin is a bit less than $1660 \mathrm{~m}$. Three other enclosed basins are inferred from the breaks in slope, one between the 1650 and $1700 \mathrm{~m}$ contours, just above the 1750 and $1850 \mathrm{~m}$ contours.

Previous mappings of the subglacial topography are shown in Figure $3 \mathrm{~b}$ based on 425 point radar measurements and 24 holes to the glacier bottom (Hodge, 1979), and in Figure $3 \mathrm{c}$ based on gravimetric measurements (Krimmel, 1970). The large-scale topography is similar in each figure, with a single large enclosed basin and the thalweg located west of the glacier center. Both maps made from ice radar soundings show a broader enclosed basin compared to that from the gravimetric measurements. On the whole, the two radar maps appear quite similar, with the largest differences in the region down-glacier from the enclosed basin, near the glacier terminus. We believe that the bed depiction based on the data from the profiling is more representative of the actual topography than the bed map based on the point measurements, because of the continuous record. This simply illustrates the advantages of the radar profiling. Although the record may occasionally suffer from a lack of clear echoes from the bed, one can interpolate with some confidence from adjacent sections of the profile where the echo is clear. Also, the profiling radar shows small-scale features in bed topography that are apparent in the profiles (Fig. 2) but which are much smaller than the contour diagrams at this scale can show.

\section{Subglacial hydrology}

Ice radar presents a tantalizing opportunity to detect water features within and below the ice, because of the strong dielectric contrast between ice and water that reflects or scatters a large fraction of the incident radar energy. From another perspective, this opportunity is sometimes the greatest obstacle to interpretation, because temperate glaciers are, in large part, saturated with water, thus providing many targets that reflect or scatter energy. This clutter not only diminishes the wave energy reaching the bed of a glacier (Watts and England, 1976), but also obscures some of the englacial or subglacial structures that we are trying to observe. In addition, reflections from an internal water cavity with parallel sides may constructively (or destructively) reinforce each other, making the feature more (or less) unidentifiable (Jacobel and Anderson, 1987). The strength of reflections from the bed depends on the nature of the ice-substrate contact. For example, parts of a glacier frozen to the bed should be distinguishable from those parts that have water at the bed (e.g. Björnsson and others, 1996). However, under temperate glaciers water presumably exists everywhere at the bed, and the problem is to distinguish the different conditions of sub- 

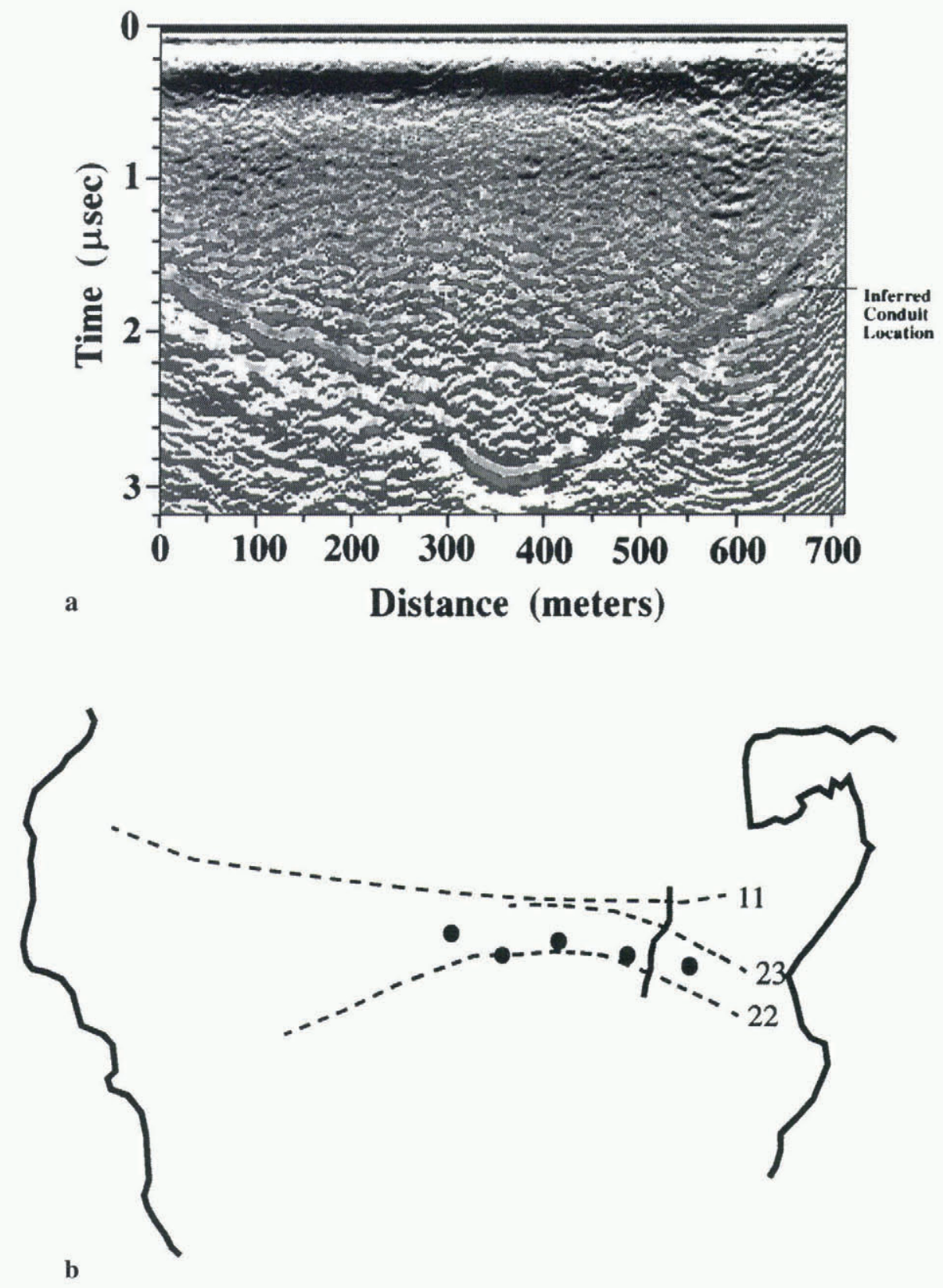

Fig. 4. (a) Radar profile 22, after migration, near the western margin. (b) A subsection of Figure 1 showing the path on the glacier surface of the radar profiles (numbered) used to trace the conduit. The view is upside down compared to that of the previous figures, such that the relation to the radar profile is correct. The thick gray line crossing each of the profiles is the inferred location of a subglacial reflector thought to be a conduit. Large dots indicate the location of boreholes drilled in 1987.

glacial water (e.g. conduits, water-saturated till, thin films over bedrock, or water-filled cavities). However, distinguishing the presence of any one condition is difficult.

Our approach is simple. Rather than attempt to explain all the variations in the brightness of basal echoes, we choose to examine only the bright echoes that appear to be relatively discrete. We then correlate the location of the echoes with the subglacial hydrology of 1986 and 1987 as described by Fountain $(1992,1994)$. One example can be seen in Figure $4 \mathrm{a}$, profile 22 near the western margin of the glacier. About $650 \mathrm{~m}$ from the start of the profile, a bright reflector can be seen. This reflector is in the vicinity of a subglacial conduit inferred from water-level measurements in the five boreholes drilled to the bottom of the glacier in 1987 (Fountain, 1994). The position of the reflector/conduit can be traced in several of our profiles, and its path is estimated
(Fig. 4b). This result also suggests that, at least during the study period, conduits existed in the same vicinity from year to year, a result consistent with inferences from geologic studies from former glacier beds (Walder and Hallet, 1979). However, more recent studies have indicated that the drainage pattern of South Cascade Glacier has changed in response to glacier thinning (Fountain and Vaughn, 1995). Therefore, we expect that the location of subglacial conduits may also be changing, and for this reason new radar results will be used to direct future drilling sites as the first step towards a predictive capability of subglacial hydrology.

\section{CONGLUSIONS}

Radar profiling provides a relatively rapid means for deter- 
mining the depth of a glacier and variations in basal topography. Profiling has the advantage over point measurements in providing a large number of measurements such that detailed variations in basal topography can be detected and the bed location can be better interpolated where the echo is obscured. Because of the rapidly changing topography common to alpine glaciers, migration is an important step in the data processing to provide a realistic determination of basal topography. Significant improvements in our understanding of the basal topography under South Cascade Glacier were achieved using the profiling radar and digital processing in comparison to that derived from point measurements. Although more work is required, we believe that the trace of bright echoes between adjacent profiles is probably indicative of a subglacial conduit. Improvements in the ice radar technology are resulting in significantly greater information from the interior of glaciers. We are now on the verge of using ice radar to derive data about subglacial hydrologic features, and continued developments in this technology will yield important contributions to our understanding of glacier hydrology and its implications for glacier movement.

\section{REFERENCES}

Björnsson, H. and 6 others. 1996. The thermal regime of sub-polar glaciers mapped by multi-frequency radio-echo sounding. f. Glaciol., 42(140), 23-32.

Bogorodsky, V.V., C. R. Bentley and P. E. Gudmandsen. 1985. Radioglaciology. Dordrecht, D. Reidel Publishing Co.

Engheta, N., C. H. Papas and C. Elachi. 1982. Radiation patterns of interfacial dipole antennas. Radio Sci., 17(6), 1557-1566.
Evans, S. 1963. Radio techniques for the measurement of ice thickness. Polar Rec., 11 (73), 406-410.

Fountain, A. G. 1992. Subglacial water flow inferred from stream measurements at South Cascade Glacier, Washington, U.S.A. F. Glaciol., 38(128), $51-64$.

Fountain, A. G. 1994. Borehole water-level variations and implications for the subglacial hydraulics of South Cascade Glacier, Washington State, U.S.A. 7. Glaciol., 40(135), 293-304.

Fountain, A. G. and B. H. Vaughn. 1995. Changing drainage patterns within South Cascade Glacier, Washington, USA, 1964-1992. International Association of Hydrological Sciences Publication 228 (Symposium at Boulder 1995 - Biogeochemistry of Seasonally Snow-Covered Catchments), $379-386$.

Hodge, S. M. 1979. Direct measurement of basal water pressures: progress and problems. 7. Glaciol., 23(89), 309-319.

Jacobel, R.W. and S. K. Anderson. 1987. Interpretation of radio-echo returns from internal water bodies in Variegated Glacier, Alaska, U.S.A. 7. Glaciol., 33(115), $319-323$.

Jacobel, R.W., A. M. Gades, D. L. Gottschling, S. M. Hodge and D. L. Wright. 1993. Interpretation of radar-detected internal layer folding in West Antarctic ice streams. 7. Glaciol., 39(133), 528-537.

Krimmel, R. M. 1970. Gravimetric ice thickness determination, South Cascade Glacier, Washington. Northwest Sci., 44(3), 147-153.

Krimmel, R. M. 1989. Mass balance and volume of South Cascade Glacier, Washington, 1958-1985. In Oerlemans, J., ed. Glacier fluctuations and climatic change. Dordrecht, etc., Kluwer Academic Publishers, 193-206.

Krimmel, R. M. 1995. Water, ice, and meteorological measurements at South Cascade Glacier, Washington, 1994 balance year. U.S. Geol. Surv. Water-Resour. Invest. Rep. 95-4162.

Narod, B. B. and G. K. C. Clarke. 1994. Miniature high-power impulse transmitter for radio-echo sounding. 7. Glaciol., 40(134), 190-194.

Walder, J. and B. Hallet. 1979. Geometry of former subglacial water channels and cavities. 7. Glaciol., 23(89), 335-346.

Watts, R. D. and A.W. England. 1976. Radio-echo sounding of temperate glaciers: ice properties and sounder design criteria. f. Glaciol., 17(75), $39-48$.

Yilmaz, O. 1987. Seismic data processing. Tulsa, OK, Society of Exploration Geophysicists. (Investigations in Geophysics 2.) 